\title{
Adverse Event Pre-specified
}

National Cancer Institute

\section{Source}

National Cancer Institute. Adverse Event Pre-specified. NCI Thesaurus. Code C87840.

An indication or description that an adverse event was previously determined,

characterized, or detailed. 